\title{
812 Correspondence
}

consistently given fraudulent clinical histories and fabricated signs so causing their children needless clinical investigations and treatments. More than 60 cases have come to light in England and Scotland alone; I am grateful to the paediatricians and others who have kept me informed.

An unexpected consequence of the national publicity which resulted from the article in this journal has been that a number of parents have contacted me directly wishing to confess that they have been indulging in Munchausen syndrome by proxy, or alleging that their spouse is. Checking their stories and arranging appropriate help has been a difficult and sensitive task. From it I have learnt that Munchausen syndrome by proxy is more common than even I imagined, and that the bizarre fabrications in which mothers may indulge are limitless. However, by far the most common fabrication in this group of parents has been a long false story of seizures in their child-that is epilepsy. Such fabrication is easy to maintain since doctors rarely see a child having a seizure. Moreover the story is particularly likely to achieve hospital admission or referral to a specialist. It is noteworthy that most of these mothers do not have a nursing or medical background: ex-nurses seem to invent more exotic diseases than epilepsy. One lesson to be learnt is that paediatricians should take the opportunity to check the veracity of any seizure which is alleged to have occurred at school or in the presence of a third party who can act as an independent witness. This is particularly necessary for any child who seems to have an unusual form of epilepsy, or one who is allegedly unresponsive to treatment. A fuller report of these cases will follow.

Reference
1 Meadow R. Munchausen syndrome by proxy. Arch Dis
Child 1982; 57: 92-8.
Roy MEADow
Department of Paediatrics and
Child Health,
St James's University Hospital,
Leeds LS9 7TF

Ultrasound in Pediatrics. Edited by J O Haller and A Shkolnik. Volume 8 in Clinics in Diagnostic Ultrasound Series. (Pp. 306 incl. index; illustrated + tables. $£ 15.00$ hardback.) Churchill Livingstone: New York. 1981.

Twenty-three authors, 15 chapters, and 264 pages cover almost everything from the neonatal brain to the scrotum (excluding echocardiography). Many of the authors are well known, some particularly so for their contributions to paediatric ultrasound; therefore one would expect this book to be a flagship of North American paediatric ultrasound but, unfortunately, it falls far short of such great expectations. Most of the images are poor but as the standard of production is high this is not the publisher's fault.

Similar topics are discussed in several chapters and this repetition should have been eliminated by the editors. The chapters on antenatal diagnosis, the chest, the pelvis, and the scrotum are all very good. 'High resolution ultrasound' surprisingly proved to be a little gem and dealt with biliary atresia more efficiently than the major chapter on the subject; it is the only chapter in which visualisation of the normal newborn biliary tree is mentioned. I disagree with the suggested measurement of the bile duct lumen as $3 \mathrm{~mm}$ in the child; up to $1.5 \mathrm{~mm}$ in the newborn and $2 \mathrm{~mm}$ in the child up to age 10 would be more accurate.

Although the chapter on the neonatal brain is good it is weakened by poor images and lack of detail on periventricular haemorrhage, and the chapter on the liver and digestive system is disappointing and cannot be recommended as a good source of information. The chapters on the urinary tract were well written, but the illustrations were either bad or indeterminable. For example, figure 8.14 was supposed to be of acute tubular necrosis but it could be renal venous thrombosis; 8.15 may be glycogen storage disease but is not the picture one would expect to be used to illustrate this condition; 8.18 was supposed to demonstrate the right adrenal but in fact indicates the right crus of the diaphragm!

This book is good in parts but regrettably its many weaknesses will prevent it from becoming a leading text on the subject.

C METREWELI

\section{Shorter notices}

Common Symptoms of Diseases in Children, seventh edition. By R S Illingworth. (Pp. 367 incl. index; tables. $£ 9.50$ hardback.) Blackwell: Oxford. 1982.

The latest edition of this popular book contains many revisions but the basic structure is unchanged. At least 100 symptoms are carefully considered and, where appropriate, a list of the פof important causes given. Although gape causes of the symptom are included care has been taken to stress the more Fiky common causes.

Textbook of Paediatric Nutrition, secoñd edition. Edited by D McLaren a d D Burman. (Pp. 464 incl. index; illustrated + tables. $£ 16.00$ paperbac?) Churchill Livingstone: Edinburgh. 1982

It is six years since this was first publishe The latest edition contains important ney sections and, in particular, deals wh some of the more topical and contentious aspects of nutrition; this is achieved without interfering with its sensible and comprehensive approach. The price ss modest considering the size and scope of the book.

Understanding Child Abuse. Edited D M Jones. (Pp. 299 incl. index. £2. paperback.) Hodder \& Stoughton: Severooaks. 1982.

This small book is a useful introduction to child abuse for inexperienced paediatricians. Descriptions of the socilal services and the various laws relating to children are admirably clear, but th\&r inclusion limits the book to a British readership. 